\title{
Flash-Related Synchronization and Desynchronization Revealed by a Multiple Band Frequency Analysis
}

\author{
Ichiro SHIMOYAMA, Yasuhumi KASAGI, Takehito KAIHO, Tadahiko SHIBATA, \\ Yoshio NAKAJIMA, and Humitaka ASANO* \\ Department of Physiology, School of Medicine, Chiba University, Chiba, \\ 260-8670 Japan; and *Gram Corporation, Urawa, 336-0006 Japan
}

\begin{abstract}
The fast Fourier transform (FFT) is a good method to estimate power spectral density (PSD), but the frequency resolution is limited to the sampling window, and thus the precise characteristics of PSD for short signals are not clear. To relax the limitation, a multiple band-pass filter was introduced to estimate the precise course of PSDs for flash visual evoked potentials (VEPs). Signals were recorded during -200 and $600 \mathrm{~ms}$ using balanced noncephalic electrodes, and sampled at $1,000 \mathrm{~Hz}$ in 12 bits. With $1 \mathrm{~Hz}$ and 10 $\mathrm{ms}$ resolutions, PSDs were estimated between 10 and $100 \mathrm{~Hz}$. Background powers at the alphaand beta-bands were high over the posterior scalp, and powers around $200 \mathrm{~ms}$ were evoked
\end{abstract}

at the same bands over the same region, corresponding to P110 and N165 of VEPs. Normalized PSDs showed evoked powers around 200 ms and suppressed powers following the evoked powers over the posterior scalp. The evoked powers above the $20 \mathrm{~Hz}$ band were not statistically significant, however, the gamma band was significantly evoked intra-individually; details in the gamma bands were varied among the subjects. Details of PSDs were complicated even for a simple task such as watching flashes; both synchronization and desynchronization occurred with different distributions and different time courses. [Japanese Journal of Physiology, 50, 553-559, 2000]

Key words: band-pass filter, power spectral density, resolution, FFT, VEPs.

Gamma-band fluctuation has been studied for the brain slice [1], alert monkeys [2] and humans [3-8], but gamma-band oscillation is inconclusive in detail. Major reports have discussed the synchronization of the gamma-band as brain activation, and a few groups have reported desynchronization in the performance of tasks $[9,10]$. The timing of gamma-band oscillation has been reported to differ depending on the task [11], and different frequencies have been generated over different areas [12]. The temporal and spatial distributions of the gamma band differed according to high and low gamma-band synchronization, and low gamma-band synchronization was parallel to alphaband desynchronization [13]. The gamma-band oscillation and alpha-band oscillation were discussed as two independent brain activities and two different functional implications [14]. The frequency of the gamma-band activity was found to be dependent on the sensory modality [15]. In the analysis of gammaband signals, fast Fourier transform (FFT) has been a powerful method to estimate power spectral density (PSD) $[16,17]$; however, FFT has a limitation in that the frequency resolution is in inverse proportion to the temporal resolution [frequency resolution] $=1 /$ [temporal resolution]. The temporal and frequency resolutions are critical for the analysis of time series signals, so FFT is not appropriate for examining the fine structure of the event [18]. Running spectral analysis [8, 13, 19] and zero padding methods [20] have been used to study the spectral time course. However, with those methods, the actual time window was wider than the temporal resolution and the same data were used repeatedly, so the results were averaged, resulting in a low signal-to-noise ratio. Wavelet analysis [21]

Received on April 27, 2000; accepted on August 29, 2000

Correspondence should be addressed to: Ichiro Shimoyama, Department of Physiology, School of Medicine, Chiba University, Chiba, 260-8670 Japan. Tel: +81-43-226-2027. Fax : +81-43-226-2028, E-mail: ichiro@med.m.chiba-u.ac.jp 
and the maximum entropy method (MEM) $[22,23]$ have been employed to study short signals, but these are not appropriate to study the course of the power, as the results are very sensitive to the complex parameters. A new algorithm, which is not dependent on FFT, is necessary to estimate the precise time course of VEPs without limitations. A multiple band-pass filter [24] was introduced to estimate PSDs with $1 \mathrm{~Hz}$ resolution induced by a simple task such as watching flashes, and the temporal and spatial distributions were studied for VEPs.

\section{MATERIALS AND METHODS}

Subjects. Six volunteers, aged $33.8 \pm 9.5$ (mean $\pm \mathrm{SD}$ ) years, participated in this study after a full explanation of the study and obtaining voluntary consent from all subjects. The vision was normal or adequately corrected for refraction.

Tasks. The subject, after a period of dark adaptation for $30 \mathrm{~min}$, was asked to watch a binocular stroboscope $(0.1 \mathrm{~J}, 3 \times 3 \mathrm{~cm})$ set $1 \mathrm{~m}$ from the subject. The inter-stimuli-intervals were between 2 and $4 \mathrm{~s}$. The stimuli were given more than 50 times for one subject and 50 VEPs were selected after careful observation to reject artifacts.

Recording. Twenty-one scalp electrodes were placed according to the International 10/20 system with the balanced non-cephalic reference [24]. The signals were recorded between 0.5 and $100 \mathrm{~Hz}(-6$ $\mathrm{dB} /$ octave) and sampled at $1,000 \mathrm{~Hz}$ during the prestimulus $200 \mathrm{~ms}$ and post-stimulus $600 \mathrm{~ms}$. Zero levels were defined as the mean potentials of the pre-stimulus $200 \mathrm{~ms}$ for each signal.

Algorithm. Multiple band frequency analysis (MBFA) [25]: Figure 1 (upper) was a block diagram of this algorithm, band-pass filters were applied to a signal (infinite impulse response, 2nd-order recursive filter), and the mean amplitude within a time window was estimated for every band. When the width of the band of the wavelength was shorter than the time window, the mean amplitude was estimated using the peaks and valleys. For the band of the wavelength, which was longer than the time window, the window was temporally widened to include the nearest peak or valley and then the amplitude was estimated. In the case of the sampling clock at $1,000 \mathrm{~Hz}$, the minimum bandwidth was $1 \mathrm{~Hz}$, the lowest band was $4.5-5.5 \mathrm{~Hz}$ and the highest band was $299.5-300.5 \mathrm{~Hz}$. The minimum time window was $10 \mathrm{~ms}$.

Procedures. A control signal, sweeping a sine wave from 5 to $100 \mathrm{~Hz}$ during $1 \mathrm{~s}$, was tested (Multifunction synthesizer-1941, NF Electronic Inst., Tokyo
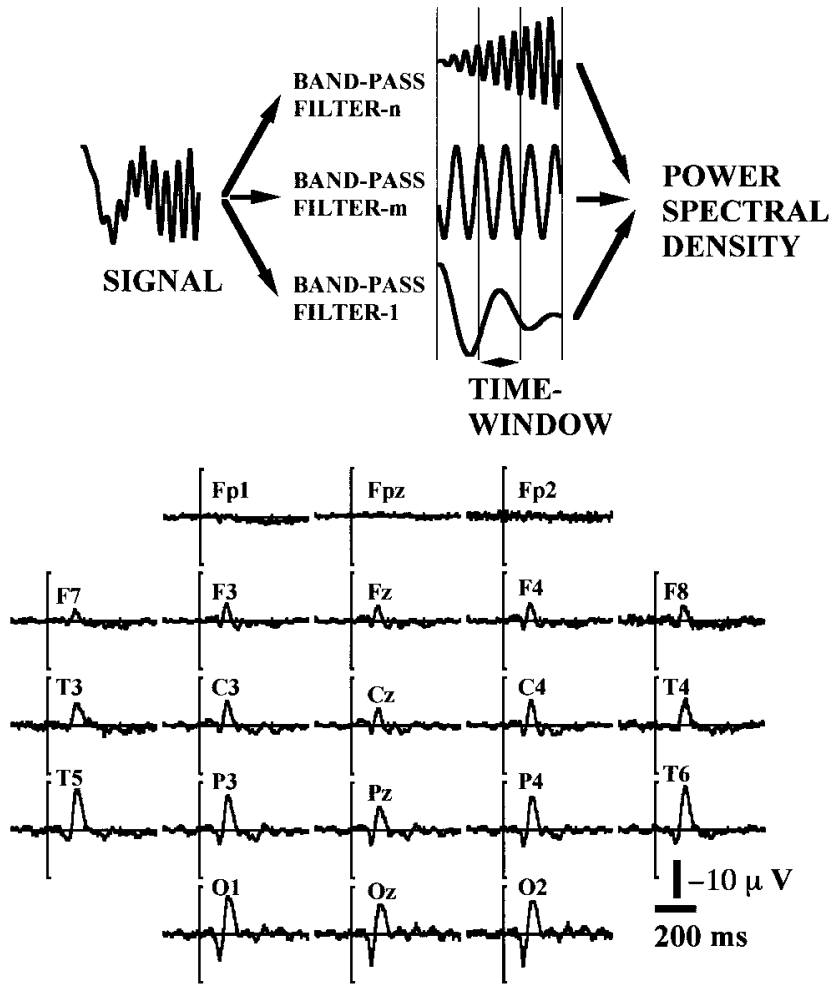

Fig. 1. Upper: Block diagram for the algorithm. The signal was analyzed with multiple band-pass filters (I, $m, n)$, and the mean amplitudes for a specific window for each band were estimated. Lower: Total average visual evoked potentials.

Japan), which was sampled at $1,000 \mathrm{~Hz}$ in 12 bits (Fig. 2A). The control signal was analyzed with MBFA, wavelet analysis, the maximum entropy method (MEM), and FFT using the zero padding method. For VEPs, 50 evoked potentials were analyzed with MBFA to obtain mean PSDs. Then normalized PSDs were transformed in decibels using the mean power of the pre-stimulus $200 \mathrm{~ms}$ for the corresponding band. Each $10 \mathrm{~ms}$ signal was serially analyzed with $1 \mathrm{~Hz}$ resolution and 10-ms resolution without overlapping the data. The total average VEPs were calculated to compare PSDs.

Statistics. Multivariable analysis of variance (MANOVA) was employed to test for the effect of the recording sites for each band using the mean amplitudes during 200 -ms epoch (4 epochs $\times 21$ sites, Systat 5.2.1). For the significant bands, one-way repeated measures MANOVA was used for each site to estimate the epoch with significant changes (4 epochs). Factorial analysis of variance (ANOVA) was used to test the intra-individual variance, testing the effect of bands with significantly synchronized evoked power ( 4 epochs $\times 21$ sites, Fisher's LSD). 


\section{RESULTS}

Figure 2 B-E shows the compressed spectral arrays (CSA) estimated for the control signal. As shown in Fig. 2B (CSA with MBFA), there was a linear increase in the peak frequency from the 10 to $100 \mathrm{~Hz}$ bands, but the peak frequencies below the $10 \mathrm{~Hz}$ band were nonlinear. Figure $2 \mathrm{C}$ showed a fairly linear increase in the peak frequency above the $10 \mathrm{~Hz}$ band, but the dominant power was decreased for the higher frequency bands and the frequency of the dominant power was increased in a stepwise manner. Figure 2D shows the various powers for the peak frequency throughout the course. The precise course of the powers could not be estimated for Fig. 2E. Figure 1 (lower) gives total average VEPs. A positive peak at $110 \mathrm{~ms}$ and a negative peak at $165 \mathrm{~ms}$ were measured at the right occipital pole $(\mathrm{O} 2)$, and similar responses were distributed all over the scalp except for the frontal poles (Fp1, Fpz and FP2). Figure 3 (upper) shows total average PSDs; the powers above the $15 \mathrm{~Hz}$ band were very low for all sites, the powers below the $15 \mathrm{~Hz}$ band were high not only for the background powers but also for the evoked powers. The evoked powers were noted around $200 \mathrm{~ms}$ at the alpha and beta bands, which were maximal over the occipital poles $(\mathrm{O} 1, \mathrm{Oz}$ and $\mathrm{O} 2)$. MANOVA gave significant results at the bands between 10 and $19 \mathrm{~Hz}(d f=3,103$, $p<0.05$ ). One-way repeated measures MANOVA showed a significant change between the epochs (Table 1). Significant differences were noted around the $10 \mathrm{~Hz}$ band between the pre-stimulus epoch and post-stimulus $0-200 \mathrm{~ms}$, and between post-stimulus 0-200 ms and post-stimulus $200-400 \mathrm{~ms}$. Around the 18 and $19 \mathrm{~Hz}$ bands, significant changes were noted between post-stimulus $200-400 \mathrm{~ms}$ and post-stimulus $400-600 \mathrm{~ms}$, and between pre-stimulus epoch and post-stimulus $0-200 \mathrm{~ms}$. Around the $15 \mathrm{~Hz}$ band, significant changes were noted between post-stimulus 0 $200 \mathrm{~ms}$ and post-stimulus $200-400 \mathrm{~ms}$, and between post-stimulus $200-400 \mathrm{~ms}$ and post-stimulus $400-600$ ms. To test intra-individual significance $(d f=3,60$, $p<0.05$ ), the effect of epoch was significant at the $10-16,31-32,39-42,48-49,52-54,57-58,63-66$, $77-81$ and $88-90 \mathrm{~Hz}$ bands, and the interactions between epoch and site were significant at the 10-17, $38-42,44,57-59,93 \mathrm{~Hz}$ bands. Figure 3 (lower) provides the normalized total average PSDs. The evoked powers around $200 \mathrm{~ms}$ at the alpha and beta bands were enhanced over the whole scalp, and the evoked powers were noted even over the frontal areas (F8, F4, Fz, F3, F7, Fp2, Fpz and Fp1). The evoked powers occurred around $100 \mathrm{~ms}$ and lasted around $400 \mathrm{~ms}$. The
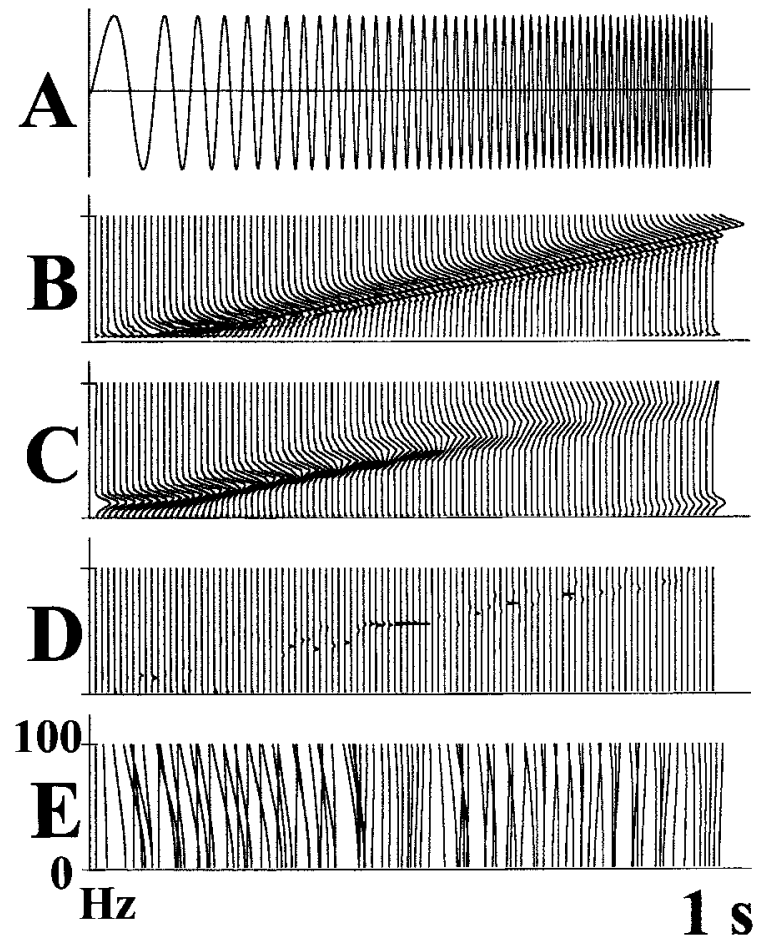

Fig. 2. A: Control signal, sine was swept 5 to $100 \mathrm{~Hz}$ in $1 \mathrm{~s}$. B: Compressed spectral arrays (CSA) analyzed with multiple band-pass filters. C: CSA analyzed by the wavelet method. D: CSA with maximum entropy method. E: CSA with FFT using the zero padding method. Power was normalized with the maximal value for the analytical method to make CSA.

maximum evoked powers at the alpha and betabands were centered over the occipital poles around $140 \mathrm{~ms}$ (O1, Oz and O2). Suppression of power at the alpha and beta bands followed the evoked high powers over the posterior scalp, which occurred from $300 \mathrm{~ms}$ to the end of the record $(600 \mathrm{~ms})$. The suppressed powers were maximal over the bilateral posterior temporal areas (T5 and T6). The powers around the $40 \mathrm{~Hz}$ band were evoked after $200 \mathrm{~ms}$ over the occipital $(\mathrm{O} 1, \mathrm{Oz}$ and $\mathrm{O} 2$ ), parietal (P3, Pz and $\mathrm{P} 4)$, central $(\mathrm{C} 3, \mathrm{Cz}$ and $\mathrm{C} 4)$ and frontal areas (F3, Fz and F4), which showed a maximum over the occipital area $(\mathrm{O} 1)$. The powers above the $30 \mathrm{~Hz}$ band were noted to be high after 400 ms over the central (C3, Cz and C4), frontal (F3, Fz and F4) and parietal areas (P3, Pz and P4): the powers were diffusely distributed over the central areas. The evoked powers above the $30 \mathrm{~Hz}$ band occurred discontinuously between the 30 and $100 \mathrm{~Hz}$ bands. PSDs over the frontal poles (Fp1, Fpz and Fp2) showed no characteristic features.

\section{DISCUSSION}

Multiple band frequency analysis. For the 

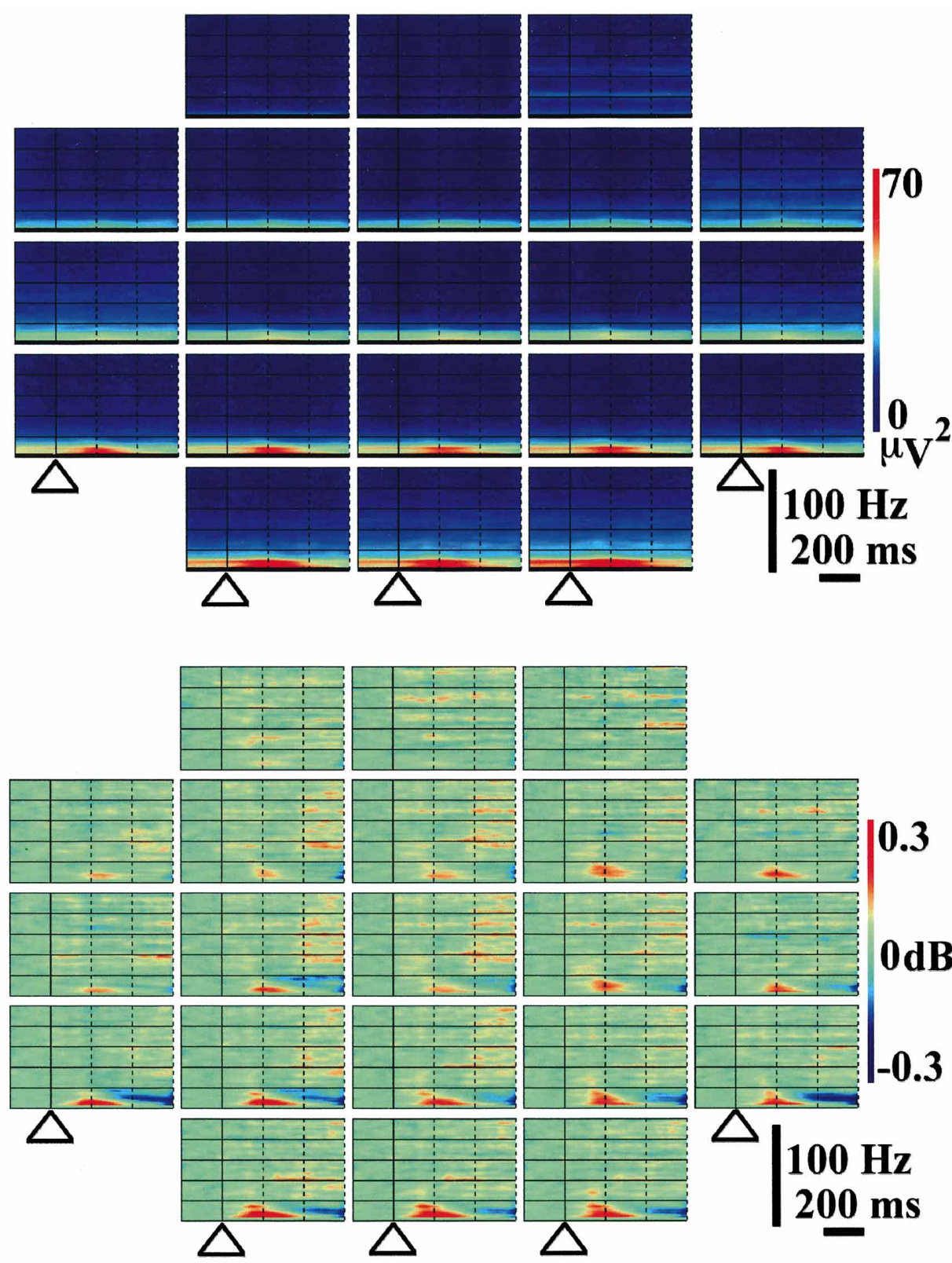

control signal, MBFA achieved a good estimation for PSDs with $1 \mathrm{~Hz}$ and $10 \mathrm{~ms}$ resolutions; the peak frequency above the $10 \mathrm{~Hz}$ band showed a linear relationship to the signal and the powers were constant (Fig. 2B). Wavelet analysis [21] is a method used for localized variations of power within a time series; the frequency resolution was not linear but in an exponential series, and thus it was difficult to analyze signals with $1 \mathrm{~Hz}$ resolution. The Burg method or MEM [22, 23] are other methods used to estimate short signals with smooth resolution; however, the estimated power was extremely sensitive to the poles used in the analysis, and the power did not reflect the signal amplitude, and therefore, these methods are not appropriate to study the course of power. FFT with the zero padding method [20] was considered for the short window, but

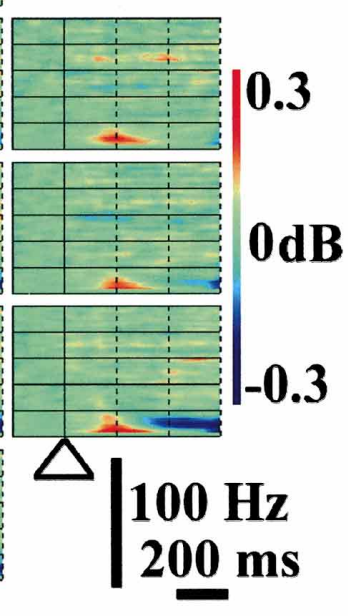

Fig. 3. Upper: Total average power spectral densities. The triangles represent the stimulus onset. Electrode positions were the same as those in Fig. 1, lower. Lower: Normalized total average spectral power densities.

it was very difficult to estimate PSDs (Fig. 2E).

Flash-related PSDs. The absolute powers of the PSDs showed marked differences between the powers below the $15 \mathrm{~Hz}$ band and those above the 15 Hz band (Fig. 3, upper). The normalized PSDs (Fig. 3, lower) showed different patterns from the absolute PSDs; the evoked powers around $200 \mathrm{~ms}$ were enhanced over broad areas as far as the frontal poles and the maximum powers were noted over the occipital poles. The suppressed powers, following the evoked powers, at the alpha and beta bands were enhanced, and the suppressed powers were maximal over the bilateral posterior temporal areas. The above two findings were marked over the posterior scalp, but the distribution of responses was different (Table 1); differences between the epochs (the pre-trigger $200 \mathrm{~ms}$ ver- 
Table 1. Statistics for various significant bands.

\begin{tabular}{|c|c|c|c|c|c|c|c|c|c|c|}
\hline \multirow{2}{*}{ Site } & \multicolumn{10}{|c|}{ Band $(\mathrm{Hz})$} \\
\hline & 10 & 11 & 12 & 13 & 14 & 15 & 16 & 17 & 18 & 19 \\
\hline \multicolumn{11}{|l|}{ FP1 } \\
\hline \multirow{2}{*}{\multicolumn{11}{|c|}{$\begin{array}{l}\text { Fp2 } \\
\text { F3 }\end{array}$}} \\
\hline F3 & & & & & & & & & & \\
\hline F4 & & & & & & $(2)^{\star}$ & $(2)^{\star}$ & * & & \\
\hline C3 & & & & & & $(3)^{*}$ & & & & $(3)^{*}$ \\
\hline C4 & & & & & & $\star$ & & & $(3)^{\star}$ & $(3)^{*}$ \\
\hline P3 & $(1,2)^{\star}$ & & & $(1)^{\star}$ & * & & & & $(1,3)^{\star}$ & $(1,3)^{\star}$ \\
\hline P4 & & & & & & & & & $(3)^{\star}$ & \\
\hline 01 & $(1)^{\star}$ & & & & & & & & $(3)^{\star}$ & $(3)^{*}$ \\
\hline $\mathrm{O} 2$ & $(1,2)^{*}$ & & & & $(1,2,3)^{\star}$ & $(2,3)^{\star}$ & & & $(1,3)^{\star}$ & $(3)^{*}$ \\
\hline F7 & & & & & & & & & & \\
\hline \multicolumn{8}{|l|}{ F8 } & & & \\
\hline \multicolumn{11}{|l|}{ T3 } \\
\hline \multicolumn{11}{|l|}{$\mathrm{T} 4$} \\
\hline T5 & $(1,2)^{\star}$ & $(1,2)^{*}$ & & & & & & $(1,3)^{\star}$ & $(1,3)^{\star}$ & $(1,3)^{\star}$ \\
\hline T6 & & & $(1)^{\star}$ & & & $(3)^{\star}$ & & & $(3)^{*}$ & \\
\hline \multicolumn{11}{|l|}{ Fpz } \\
\hline \multicolumn{11}{|l|}{$\mathrm{Fz}$} \\
\hline $\mathrm{Cz}$ & & & & & & & & & & \\
\hline $\mathrm{Pz}$ & & & & & & & & & $(3)^{\star}$ & \\
\hline $\mathrm{Oz}$ & & & & & & & & & & $(3)^{\star}$ \\
\hline
\end{tabular}

* Singnificant. 1: significant change between prestimulus 200 and 0-200 ms. 2: significant change between 0-200 and 200-400 ms. 3: significant change between $200-400$ and 400-600 ms.

sus post-trigger $0-200 \mathrm{~ms}$ ) were significant over P3, O1, O2, T5, and T6. Differences between the epochs (post-trigger $200-400$ versus $400-600 \mathrm{~ms}$ ) were significant over C3, C4, P3, P4, O1, O2, T5, T6, Pz, and Oz. The above results suggested two different functional states of cell assemblies. The evoked powers above the $20 \mathrm{~Hz}$ band were not significant inter-individually, but they were significant intra-individually. The precise evoked gamma oscillation was varied inter-individually and had a complicated time course.

Range of gamma-band. Jasper and Andrews [26] reported gamma rhythm to designate frequencies above 30 or $35 \mathrm{~Hz}$, but gamma frequencies are now simply considered a part of the beta range [27]. The reported range of the gamma band is varied; 20-50 [6], 30-70 [28], 30-110 [15], and about $40 \mathrm{~Hz}$ [29]. As Crone et al. [13] have reported the cortical processing in classifying the gamma band into two bands, the gamma band must be classified in detail when discussing the brain function. With FFT, the frequency resolution was restricted to the time window, and when temporal resolution was selected to be rather narrow, the frequency resolution was rather wide. Therefore, the characteristics of the gamma band could not be estimated with FFT. But, MBFA could be used to estimate PSDs with $1 \mathrm{~Hz}$ and $10 \mathrm{~ms}$ resolu- tions, and the two parameters were not dependent upon each other.

Synchronization or desynchronization. Reports about the gamma-band responses have discussed synchronization of the band, but few studies have discussed desynchronization in relation to brain function $[9,13]$. Here, synchronization was thought to correspond to evoked high powers and desynchronization was thought to correspond to the suppressed powers. PSDs with $1 \mathrm{~Hz}$ and $10 \mathrm{~ms}$ resolutions showed complex patterns: certain bands showed powers evoked high, some bands showed powers unchanged and others showed powers suppressed.

Distribution of the gamma band. The distribution of the gamma band has been reported to be diffuse $[30,31]$. With MBFA, broad and diffuse distribution was noted for gamma-band synchronization, and different distribution was noted among the synchronization for the gamma, alpha and beta bands.

Timing of the gamma band. The gammaband oscillation was reported from $100 \mathrm{~ms}$ after the stimuli for the cat auditory system [30], but the human gamma-band oscillation for nouns and verbs was reported during post-stimulus $500-800 \mathrm{~ms}$ [7]. MBFA revealed that gamma-band synchronization around the $40 \mathrm{~Hz}$ band was noted after $200 \mathrm{~ms}$ and the 
synchronization for other gamma bands was noted after $400 \mathrm{~ms}$.

Tasks and gamma band. In the visual modality, $30-40 \mathrm{~Hz}$ EEG activity in humans was reportedly elicited by a brief steady illumination [3]. The chattering cell has contributed to the generation of synchronous cortical oscillations for the cat striate cortex [32]. The gamma-band oscillation was generated from different cell assemblies depending on the state of the subject's attention [10, 29], word cognition [7, 33], specific cognitive processes [34], perception of the multistable patterns [35], formation of percepts and memory, linguistic processing, and other behavioral and perceptual functions [36]. Most authors reported higher brain functions as cognition or perception for the gamma-band responses [28, 37], but PSDs showed the details of complicated responses within the gamma band, even in response to the simple task of watching flashes.

Evoked potentials and gamma band. The source of evoked potential (N1) and gamma-band oscillation has been different [38]. The initial full activation is around $200 \mathrm{~ms}$ for the event-related potentials, and continuous reverberatory activities were thought to be gamma-band oscillation around $30 \mathrm{~Hz}$ post-stimulus $500-800 \mathrm{~ms}$, indicating two different functional states of cell assemblies [7]. MBFA suggests that the evoked powers below the $15 \mathrm{~Hz}$ band $(100-400 \mathrm{~ms})$ correspond to the remarkable peaks of VEPs (P110 and N165), and the distribution for the evoked powers below the $15 \mathrm{~Hz}$ band correspond to that for the peaks of VEPs. But the gamma band above the $30 \mathrm{~Hz}$ band showed a different distribution from the peaks of VEPs; gamma-band synchronization occurred after $200 \mathrm{~ms}$ and showed a different distribution than that of the peaks of VEPs.

Alpha and beta bands versus gamma band. The induced gamma-band activity is reported to be independent of the alpha-band change [14], and the low gamma band event-related synchronization is parallel to the alpha band event-related desynchronization [13]. The evoked high power and suppressed powers occurred over different distributions and different time courses for the normalized PSDs at the alpha and beta bands. But the gamma-band synchronization and alpha- and beta-band desynchronization did not occur over the same distribution. Further, our results showed a different distribution between the gamma-band synchronization and the alpha- and beta-band-desynchronization, which suggests that different cell assemblies were elicited.

In conclusion, even for simple stimuli such as flashes, detailed PSDs, as analyzed by MBFA, could be used to estimate alpha- and beta-band synchronization and desynchronization as the two responses occur over different areas. Gamma-band synchronization was observed in detail, and various bands were evoked among subjects. MBFA estimated the synchronization and desynchronization in detail, not only for the gamma band but also for the alpha and beta bands.

\section{REFERENCES}

1. Metherate R and Cruikshank SJ: Thalamocortical inputs trigger a propagating envelope of gamma-band activity in auditory cortex in vitro. Exp Brain Res 126: 160-174, 1999

2. Donoghue JP, Sanes JN, Hatsopoulos NG, and Gaal G: Neural discharge and local field potential oscillations in primate motor cortex during voluntary movements. J Neurophysiol 79: 159-173, 1998

3. Chatrian GE, Bickford RG, and Uihleim A: Depth electrographic study of a fast rhythm evoked from the human calcarin region by steady illumination. Electroencephalogr Clin Neurophysiol 12: 167-176, 1960

4. Pantev C, Makeig S, Hoke M, Galambos R, Hampson S, and Gallen C: Human auditory evoked gamma-band magnetic fields. Proc Natl Acad Sci USA 88: 89969000, 1991

5. Tallon C, Bertrand O, Bouchet $\mathrm{P}$, and Pernier J: Gamma-range activity evoked by coherent visual stimuli in humans. Eur J Neurosci 7: 1285-1291, 1995

6. Menon V, Freeman WJ, Cutillo BA, Desmond JE, Ward MF, Bressler SL, Laxer KD, Barbaro N, and Gevins AS: Spatio-temporal correlations in human gamma band electrocorticograms. Electroencephalogr Clin Neurophysiol 98: 89-102, 1996

7. Pulvermuller F, Lutzenberger $\mathrm{W}$, and Preissl $\mathrm{H}$ : Nouns and verbs in the intact brain: evidence from event-related potentials and high-frequency cortical responses. Cereb Cortex 9: 497-506, 1999

8. Shibata T, Shimoyama I, Ito T, Abla D, Iwasa H, Koseki K, Yamanouchi N, Sato T, and Nakajima Y: Event-related dynamics of the gamma-band oscillation in the human brain: information processing during a GO/NOGO hand movement task. Neurosci Res 33: 215-222, 1999

9. Pfurtscheller G, Flotzinger D, and Neuper C: Differentiation between finger, toe and tongue movement in man based on $40 \mathrm{~Hz}$ EEG. Electroencephalogr Clin Neurophysiol 90: 456-460, 1994

10. Marshall L, Molle M, and Bartsch P: Event-related gamma band activity during passive and active oddball tasks. NeuroReport 7: 1517-1520, 1996

11. Yordanova J, Kolev V, and Demiralp T: Effects of task variables on the amplitude and phase-locking of auditory gamma-band responses in human. Int $\mathrm{J}$ Neurosci 92: 241-258, 1997

12. Buchner H, Gobbele R, Waberski TD, Wagner M, and Fuchs M: Evidence for independent thalamic and cortical sources involved in the generation of the visual 40 $\mathrm{Hz}$ response in humans. Neurosci Lett 269: 59-62, 1999

13. Crone NE, Miglioretti DL, Gordon B, and Lesser RP: 
Functional mapping of human sensorimotor cortex with electrocorticographic spectral analysis. II. Event-related synchronization in the gamma band. Brain 121: 2301-2315, 1998

14. Muller MM, Junghofer M, Elbert T, and Rochstroh B: Visually induced gamma band responses to coherent and incoherent motion: a replication study. NeuroReport 8: 2575-2579, 1997

15. Pantev C: Evoked and induced gamma-band activity of the human cortex. Brain Topogr 7: 321-330, 1995

16. Elliott DF and Rao KR: Fast Transforms: Algorithms, Analyses, Applications, Academic Press, New York, 1982

17. Nussbaumer HJ: Fast Fourier Transform and Convolution Algorithms, Springer-Verlag, New York, 1982

18. Freeman JW and Maurer K: Advances in brain theory give new directions to the use of the technologies of brain mapping in behavioral studies. In: Topographic Brain Mapping of EEG and Evoked Potentials, ed. Maurer K, Springer-Verlag, Berlin, pp. 118-126, 1989

19. Van Der Schee EJ and Graushuis LJ: Running spectral analysis as an aid in the representation and interpresentation of electroencephalographic signals. Med Biol Eng Comput 25: 57-62, 1987

20. Challis RE and Kitney RI: Biomedical signal processing (in four parts) (Part 3). The power spectrum and coherence function. Med Biol Eng Comput 29: 225-241, 1991

21. Torrence $\mathrm{C}$ and Compo PG: A practical guide to wavelet analysis. Bull Am Meteorol Soc 79: 61-78, 1998

22. Jaynes ET: On the rationale of maximum-entropy methods. Proc IEEE 70: 939-952, 1982

23. Patel P, Khosla D, Al-Dayeh L, and Singh M: Distributed source imaging of alpha activity using a maximum entropy principle. Clin Neurophysiol 110: 538-549, 1999

24. Stephenson WA and Gibbs FA: A balanced noncephalic reference electrode. Electroencepharogr Clin Neurophysiol 3: 237-240, 1951

25. MBFA; Patent \#59800682011 (1998), Gram Corporation, Japan

26. Jasper $\mathrm{HH}$ and Andrews HL: Electroencephalography. III. Normal differentiation of occipital and precentral regions in man. Arch Neurol Psychiatr (Chicago) 39: 96115, 1938
27. Niedermeyer E: The normal EEG of the waking adult. In: Electroencephalography, ed. Niedermeyer $\mathrm{E}$ and Lopes da Silva F, Urban \& Schwarzenberg, BaltimoreMunich, pp. 71-91, 1982

28. Tallon-Baudry C, Bertrand O, Delpuech C, and Permier $\mathrm{J}$ : Oscillatory gamma-band $(30-70 \mathrm{~Hz})$ activity induced by a visual search task in humans. J Neurosci 17: 722734, 1997

29. Tiitinen $H$, Sinkkonen $J$, Reinikainen $K$, Alho $K$, Lavikainen $\mathrm{J}$, and Naatanen R: Selective attention enhances the auditory $40-\mathrm{Hz}$ transient response in humans. Nature 364: 59-60, 1993

30. Demiralp T, Basar-Eroglu C, and Basar E: Distributed gamma band responses in the brain studied in cortex, reticular formation, hippocampus and cerebellum. Int $\mathrm{J}$ Neurosci 84: 1-13, 1996

31. Rager $G$ and Singer W: The response of cat visual cortex to flicker stimuli of variable frequency. Eur J Neurosci 10: 1856-1877, 1998

32. Gray CM and McCormick DA: Chattering cells: superficial pyramidal neurons contributing to the generation of synchronous oscillations in the visual cortex. Science 274: 109-113, 1996

33. Lutzenberger $\mathrm{W}$, Pulvermuller $\mathrm{F}$, and Birbaumer $\mathrm{N}$ : Words and pseudowords elicit distinct patterns of 30$\mathrm{Hz}$ EEG responses in humans. Neurosci Lett 176: 115118,1994

34. Pulvermuller F, Lutzenberger $W$, Preiss $H$, and Birbaumer N: Spectral responses in the gamma-band: physiological signs of higher cognitive processes? NeuroReport 6: 2059-2064, 1995

35. Basar-Eroglu C, Struber D, Kruse P, Basar E, and Stadler M: Frontal gamma-band enhancement during multistable visual perception. Int J Psychophysiol 24: 113-125, 1996

36. Miltner $\mathrm{WH}$, Braun $\mathrm{C}$, Arnold $\mathrm{M}$, Witte $\mathrm{H}$, and Taub E: Coherence of gamma-band EEG activity as a basis for associative learning. Nature 397: 434-36, 1999

37. Keil A, Muller MM, Ray WJ, Gruber T, and Elbert T: Human gamma band activity and perception of agestalt. J Neurosci 19: 7152-7161, 1999

38. Jacobson GP, Henderson J, Smith BJ, and Elisevich $\mathrm{KV}$ : High resolution recording of late cortical surface potentials N1 and gamma-band response (GBR). J Am Acad Audiol 9: 87-94, 1998 